\title{
Concentrations of hormones and metabolites in cerebrospinal fluid and plasma of dairy cows during the periparturient period
}

\author{
T. Laeger, ${ }^{*}$ H. Sauerwein, † A. Tuchscherer,‡ O. Bellmann,§ C. C. Metges, ${ }^{*}$ and B. Kuhla* \\ *Institute of Nutritional Physiology "Oskar Kellner," Leibniz Institute for Farm Animal Biology (FBN), Wilhelm-Stahl-Allee 2, 18196 Dummerstorf, \\ Germany \\ †Institute of Animal Science, Physiology \& Hygiene Unit, University of Bonn, Katzenburgweg 7-9, 53115 Bonn, Germany \\ fInstitute of Genetics and Biometry, Leibniz Institute for Farm Animal Biology (FBN), Wilhelm-Stahl-Allee 2, 18196 Dummerstorf, Germany \\ §Leibniz Institute for Farm Animal Biology (FBN), Wilhelm-Stahl-Allee 2, 18196 Dummerstorf, Germany
}

\section{ABSTRACT}

During early lactation, high-yielding dairy cows often show insufficient feed intake (FI) and, as a consequence, they enter into a negative energy balance associated with an altered pattern of plasma metabolites and hormones. These act as short- and long-term hunger or satiety signals in the brain and play an important role in the control of FI. Metabolites and hormones also occur in cerebrospinal fluid (CSF), which surrounds the hypothalamus and brainstem, 2 major centers of FI regulation. The CSF hormone and metabolite concentrations are mainly under control of the blood-brain barrier. Consequently, CSF hormone and metabolite concentrations differ from those in blood. However, the contribution of putative orexigenic and anorexigenic CSF signals possibly leading to insufficient FI of high-yielding dairy cows during early lactation has not been studied so far. Therefore, the aim of this study was to elucidate associations existing between both plasma and CSF hormones and metabolites during the periparturient period. Ten multiparous German Holstein dairy cows were fed ad libitum and samples of CSF from the spinal cord and blood from the jugular vein were withdrawn before morning feeding on $\mathrm{d}$ $-20,-10,+1,+10,+20$, and +40 relative to calving. Feed intake started to decrease from d 5 before calving and increased thereafter. Glucose, $\beta$-hydroxybutyrate (BHBA), cholesterol, nonesterified fatty acids, urea (all enzymatic), lactate (colorimetric), amino acids (HPLC), osmolality (osmometer), ghrelin (RIA), leptin (ELISA), and resistin (Western immunoblot) were measured in both CSF and plasma, whereas free fatty acids (gas chromatography-mass spectrometry) and volatile fatty acids (gas chromatography-flame-ionization de-

Received July 5, 2012.

Accepted January 9, 2013.

${ }^{1}$ Corresponding author: b.kuhla@fbn-dummerstorf.de tector) were determined in plasma only. Whereas leptin concentrations decreased after calving in both plasma and CSF, ghrelin concentrations were not altered, and abundances of total resistin and its hexamers decreased only in plasma. Although plasma concentrations of cholesterol and nonesterified fatty acids changed during the periparturient period, their concentrations were not affected in CSF. In contrast, CSF Gln concentration tended to increase until calving, whereas CSF concentrations of BHBA, $\alpha$-aminobutyric acid, Cit, Gly, Ile, Val, and Leu were increased in early lactation compared with the preparturient period. Because Gln is known to serve as neuronal substrate generating ATP, Gln is suggested to act as a central anorexigenic signal shortly before parturition. Moreover, due to their known anorexic effect, BHBA and Leu may potentially act as central signals and thereby suppress a sufficient increase in FI during early lactation.

Key words: cerebrospinal fluid, dairy cow, hormone, metabolite

\section{INTRODUCTION}

High-yielding dairy cows often show increased but inadequate feed intake (FI) during early lactation and, as a consequence, enter into a negative energy balance (EB). This period is characterized by an altered pattern of plasma metabolites, driven by an increased release of nutrients derived from body reserves and an efflux of metabolites supporting high milk production. Such an imbalanced metabolic profile also elicits moderate changes in the production and release of adipokines, which have been suggested to be essential in the prevention of sufficient FI (Ingvartsen, 2006). Both metabolites and hormones may act as satiety signals in the brain and play an important role in the control of FI. Due to the blood-brain barrier (BBB) and the blood-cerebrospinal fluid (CSF) barrier (choroid plexus epithelium), the passage of molecules between blood and neural tissue or its fluid spaces is limited 
and regulated. The transport of small molecules such as AA across the BBB may be limited by the competition among AA sharing a common transporter for the uptake into the brain (Harper and Peters, 1989). In this regard, it was recently demonstrated that, for example, concentrations of NEFA, Arg, and Leu were altered in plasma but not in CSF after a 4-d feed restriction period in dairy cows between 87 and 96 DIM (Laeger et al., 2012). Intravenous administration of metabolites such as NEFA, lactate, and Lys may reduce FI, whereas glucose is believed to play a minor role in the control of FI in ruminants (Baile and Forbes, 1974). However, when an isotonic glucose solution was injected into CSF of the third brain ventricle of sheep, FI decreased within the first $2 \mathrm{~h}$ (Seoane and Baile, 1972). Moreover, the osmolality affects FI in ruminants and tended to decrease in CSF of restrictive feed cows, whereas the osmolality is unaffected after feed restriction in plasma (Laeger et al., 2012). These findings suggest that central, rather than peripheral, mechanisms are important for the control of FI in ruminants.

Furthermore, many peptide hormones or cytokines may cross the BBB, depending on their structuralchemical characteristics by simple diffusion. Other peptide hormones are not able to cross the BBB by diffusion but use a specific saturable transport mechanism to reach the abluminal side (Fry and Ferguson, 2010). Such transport mechanisms exist for the orexigenic ghrelin (Banks et al., 2002) and for the anorexic adipokines leptin and resistin, although the transport proteins for the latter 2 are still unknown (Kos et al., 2007; Fry and Ferguson, 2010). In ruminants, intravenous injection of ghrelin (Iqbal et al., 2006) and leptin (Morrison et al., 2002) did not affect FI, whereas intracerebroventricular (i.c.v.) administration of leptin reduced FI (Morrison et al., 2001). Central administration of ghrelin, either increased (Harrison et al., 2008) or did not affect (Iqbal et al., 2006) FI in ruminants. An i.c.v. injection of resistin induces hypophagia in rodents (Cifani et al., 2009), but effects of central or peripheral resistin administrations in ruminants are still unknown.

In a first attempt to understand the interrelationship between peripheral and central metabolite and hormone signals involved in the control of FI of dairy cows, we investigated the concentrations of selected molecules during the periparturient period in both plasma and CSF. Our objective was to generate knowledge about prevailing satiety signals as a prerequisite for developing intervention strategies to counteract insufficient FI increase during early lactation. We expected to identify metabolites and hormones reflecting metabolic processes differentially regulated during the periparturient period as potential signals preventing sufficient FI in early lactation.

\section{MATERIALS AND METHODS}

\section{Animals, Husbandry, Feeding, Measurement of Zootechnical Data, and Calculation of Energy Balance}

Ten German Holstein dairy cows in second $(\mathrm{n}=9)$ and third $(\mathrm{n}=1)$ parturition were kept in tie-stalls in accordance with the guidelines for the use of animals as experimental subjects of the State Government in Mecklenburg-West Pomerania (Germany; registration no. LALLF M-V/TSD/7221.3-2.1-001/10). All cows were healthy and 44 to 52 mo old. They were fed twice daily (0700 and $1600 \mathrm{~h}$ ) a TMR ad libitum, adjusted for transition and lactation needs, respectively, consisting of corn and grass silage, grass hay, grain feed, minerals, and vitamins, to meet the energy and nutrient recommendations of dairy cows calculated according to the German Society of Nutrition Physiology (2001) [6.4 MJ of $\mathrm{NE}_{\mathrm{L}} / \mathrm{kg}$ of DM for the last $25 \mathrm{~d}$ of gestation (close-up period) and 7.2 MJ of $\mathrm{NE}_{\mathrm{L}} / \mathrm{kg}$ of DM for lactation] and sampled for CSF and plasma before morning feeding at $\mathrm{d}-20,-10,+1,+10,+20$, and +40 relative to calving. Cows had free access to water and were milked twice daily (0630 and $1530 \mathrm{~h}$ ). The daily milk yield and daily FI were measured individually. Body weight was measured once per week (see Table 1). To calculate EB, milk was analyzed for fat, protein, and lactose content by an infrared spectrophotometric method (MilkoScan; Foss GmbH, Rellingen, Germany) at the Landeskontrollverband für Leistungs- und Qualitätsprüfung Mecklenburg-Vorpommern e.V. (Güstrow, Germany). Energy-corrected milk was calculated as follows: ECM $(\mathrm{kg})=(0.038 \times \mathrm{g}$ of fat $+0.024 \times \mathrm{g}$ of protein +0.017 $\times \mathrm{g}$ of lactose $) \times \mathrm{kg}$ of milk/3.14. Energy balance [MJ of $\mathrm{NE}_{\mathrm{L}} /($ cow $\times$ day $)$ ] antepartum (EBap) and postpartum (EBpp) was calculated as EBap $=\mathrm{NE}_{\mathrm{L}}$ intake $-0.46 \times$ $\mathrm{kg}$ of $\mathrm{BW}^{0.75}$, and $\mathrm{EBpp}=\mathrm{NE}_{\mathrm{L}}$ intake $(\mathrm{MJ})-(\mathrm{ECM} \times$ $3.14+0.293 \times \mathrm{kg}$ of $\mathrm{BW}^{0.75}$ ), respectively (Reist et al., 2002). All cows were in positive EB prepartum and in negative EB postcalving until the end of the sampling period (Table 1).

\section{Blood and CSF Sampling}

After local anesthesia with $10 \mathrm{~mL}$ of Isocaine $(20 \mathrm{mg}$ of procainhydrochloride $/ \mathrm{mL}$ and $0.025 \mathrm{mg}$ of epinephrine/mL; Selectavet Dr. Otto Fischer GmbH, WeyarnHolzolling, Germany), CSF from spinal cord was obtained by lumbar puncture between the sixth lumbar vertebra and sacrum with a sharpened needle with fitted stylet (120-mm length, 1.2-mm diameter; Walter Veterinär-Instrumente e.K., Baruth/Mark, Germany), and blood was withdrawn into EDTA tubes from the 
Table 1. Energy balance (EB), $\mathrm{NE}_{\mathrm{L}}, \mathrm{BW}$, and ECM of dairy cows at the days of cerebrospinal fluid (CSF) and plasma sampling ${ }^{1}$

\begin{tabular}{|c|c|c|c|c|c|c|}
\hline Item & \multicolumn{6}{|c|}{ Days relative to parturition } \\
\hline $\mathrm{EB}\left[\mathrm{MJ}\right.$ of $\mathrm{NE}_{\mathrm{L}} /($ cow $\left.\times \mathrm{d})\right]$ & $28.4 \pm 6.0$ & $17.2 \pm 5.8$ & $-7.0 \pm 10.8$ & $-61.0 \pm 8.9$ & $-57.2 \pm 14.9$ & $-42.1 \pm 4.8$ \\
\hline $\mathrm{NE}_{\mathrm{L}}(\mathrm{MJ} / \mathrm{d})$ & $95.3 \pm 6.7$ & $83.4 \pm 5.4$ & $50.8 \pm 11.2$ & $104.9 \pm 10.1$ & $118.6 \pm 9.1$ & $126.0 \pm 16.7$ \\
\hline BW $(\mathrm{kg})$ & $765.6 \pm 21.1$ & $754.8 \pm 18.4$ & $708.4 \pm 26.8$ & $702.2 \pm 23.8$ & $688.8 \pm 24.7$ & $694.0 \pm 34.1$ \\
\hline ECM $(\mathrm{kg} / \mathrm{d})$ & & & $4.9 \pm 0.6$ & $40.1 \pm 3.4$ & $42.6 \pm 3.4$ & $42.1 \pm 3.5$ \\
\hline
\end{tabular}

${ }^{1}$ Data are presented as the mean $+\mathrm{SE}(\mathrm{n}=10)$. Energy balance, $\mathrm{NE}_{\mathrm{L}}, \mathrm{BW}$, and ECM significantly differed over time at $P<0.05(\mathrm{ANOVA})$.

jugular vein before morning feeding. Samples of $9 \mathrm{~mL}$ of blood and $5 \mathrm{~mL}$ of CSF were immediately treated with 50 or $30 \mu \mathrm{L}$ of aprotinin [Carl Roth GmbH \& Co. KG, Karlsruhe, Germany; 0.19\% (wt/vol) in $0.9 \%$ (wt/vol) $\mathrm{NaCl}$, respectively. An aliquot of $50 \mu \mathrm{L}$ of $\mathrm{CSF}$ was taken for cell count analysis using a cell counter (Multisizer II; Beckman-Coulter GmbH, Krefeld, Germany). Blood was centrifuged at $1,573 \times g$ for $20 \mathrm{~min}$ and CSF at $4,566 \times g$ for 5 min (each at $4^{\circ} \mathrm{C}$ ). Plasma and CSF aliquots were frozen in liquid nitrogen and stored at $-80^{\circ} \mathrm{C}$ for no longer than 12 mo until analyses.

\section{Analyses of Glucose, BHBA, Cholesterol, NEFA, Urea, Lactate, and AA Concentrations, FFA Profile, and Osmolality}

Glucose concentrations were determined by an automated YSI 1500-L unit (YSI Inc., Yellow Springs, OH; enzymatic assay; CV: 0.6\%). Concentrations of BHBA, cholesterol, NEFA, urea, and lactate were determined by routine analyses (Cobas Mira; Clinic for Cattle, Stiftung Tierärztliche Hochschule Hannover, Hannover, Germany) using the following commercial kits: BHBA (no. RB 1008; enzymatic assay; CV: 4.96\%) from Randox Laboratories Ltd. (Crumlin, UK), cholesterol [no. 553-124; cholesterol oxidase-phenol + aminophenazone (CHOD-PAP) method; CV: 2.58\%] from MTI Diagnostics GmbH (Idstein, Germany), NEFA [no. 434-91795; acyl-CoA-synthetase-acyl-CoA-oxidase (ACS-ACOD) assay; CV: 2.05\%] from Wako Chemicals GmbH (Neuss, Germany), urea (no. LT-UR 0050; immunoenzymatic urease method; CV: 4.93\%) from Lehmann (Berlin, Germany), and lactate (no. A11A01721; colorimetric method; CV: $2.34 \%$ ) from Horiba Europe (Montpellier, France).

Amino acid concentrations were analyzed in samples of 9 cows by HPLC [series 1200; Agilent Technologies Deutschland GmbH, Böblingen, Germany; $250 \times 4 \mathrm{~mm}$ HyperClone ODS (C18) $120 \AA$ column protected by a $4 \times 3$-mm C18 precolumn] with automated precolumn derivatization and fluorescence detection (Kuhla et al., 2010). To this end, precolumn derivatization was performed by an injector program with orthophthalaldehyde/3-mercaptopropionic acid for primary and 9-fluorenylmethoxycarbonyl chloride for secondary AA, respectively, using 3-mercaptopropionic acid as a reducing agent and iodoacetic acid to block sulfhydryl groups. Plasma FFA were derivatized to form methyl esters (FA methyl esters, FAME) using trimethylsulfonium hydroxide according to Costa et al. (1998) and analyzed using a GCMS-QP2010 gas chromatograph (Shimadzu Corp., Kyoto, Japan) on an SP-2560 column (100 m, 0.25-mm i.d.; 0.52- $\mu \mathrm{m}$ film thickness; Omnilab Laborzentrum GmbH \& Co. KG, Bremen, Germany). The concentrations of plasma VFA were determined by gas chromatography-flame ionization detector (GCFID; series 17A; Shimadzu Corp.) on an RTX-1701 column (30 m, 0.32 i.d., 0.5- $\mu \mathrm{m}$ film thickness; CZT GmbH, Kriftel, Germany) according to Kristensen et al. (2000). The osmolality was determined by using an automatic cryoscopic osmometer (Osmomat 030; Gonotec $\mathrm{GmbH}$, Berlin, Germany; CV: 0.5\%).

\section{Immunoassay Determination of Ghrelin and Leptin}

Concentrations of acylated ghrelin in both plasma and CSF were determined in samples of 6 cows with an RIA according to the procedure recommended by the manufacturer (no. GHRA-88HK; Linco Research, St. Charles, MO). This assay is specific for the first 11 AA of the $\mathrm{N}$ terminus of ghrelin, including the octanoyl moiety. The sensitivity for the ghrelin assay was $7.8 \mathrm{pg} /$ $\mathrm{mL}$. Measurements in CSF were performed in evaporated samples reduced to 25 to $50 \%$ of the original volume. The concentration of plasma leptin was determined in samples of 6 cows by a double antibody enzyme immunoassay as previously described (Sauerwein et al., 2004). In detail, the minimal detectable concentration of leptin with this assay was $0.3 \mathrm{ng} / \mathrm{mL}$ and the intraand interassay coefficients of variation were 3.6 and $7.8 \%$, respectively. For determination of CSF leptin, 3 $\mathrm{mL}$ of CSF were lyophilized and redissolved in $300 \mu \mathrm{L}$ of water before analysis.

\section{Western Immunoblot Analysis of Resistin}

Plasma $(10 \mu \mathrm{L})$ and CSF $(20 \mu \mathrm{L})$ of 10 cows were treated with 60 and $20 \mu \mathrm{L}$ Laemmli buffer, and were boiled 
for $7 \mathrm{~min}$ and $3 \mathrm{~min}$, respectively. The protocol excluded mercaptoethanol/dithiothreitol (DTT) treatment of the samples, allowing the detection of the different multimeric resistin forms. Laemmli-treated plasma $(6 \mu \mathrm{L})$ and Laemmli-treated CSF $(20 \mu \mathrm{L})$ were subjected to electrophoresis on a $12 \%$ (wt/vol) SDS-polyacrylamide gel. Proteins were then transferred to nitrocellulose membranes. Membranes were blocked with $3 \%$ (wt/ vol) BSA in TBST buffer $(20 \mathrm{~m} M$ Tris- $\mathrm{HCl}, 0.9 \%$ (wt/ vol) $\mathrm{NaCl}$, and $0.05 \%$ (vol/vol) Tween-20; $\mathrm{pH} 7.6$ ) and subsequently incubated with the primary rabbit antiserum raised against a bovine resistin homolog sequence (ab14324; Abcam PLC, Cambridge, MA) at $4^{\circ} \mathrm{C}$ for 12 $\mathrm{h}$ (1:1,000 dilution). Membranes were then washed with TBST buffer and afterward incubated with horseradish peroxidase (HRP) conjugated anti-rabbit IgG (1:10,000; Santa Cruz Biotechnology Inc., Santa Cruz, CA) for $60 \mathrm{~min}$ at room temperature. After 3 times of washing with TBST, membranes were transferred to enhanced chemiluminescence (ECL) solution and exposed to Xray films. Bands were scanned and quantified based on gray values using ImageJ software (version 1.42q; National Institutes of Health, Bethesda, MD).

\section{Statistical Analyses}

Statistical evaluation was performed using SAS (version 9.3; SAS Institute Inc., Cary, NC). All response variables were analyzed by repeated measures ANOVA applying PROC GLIMMIX. Repeated measures on the same animal were taken into account by the residual option in the random statement of PROC GLIMMIX to construct the block diagonal structure of the residual covariance matrix for each animal. The one-way ANOVA model for analysis of $\mathrm{NE}_{\mathrm{L}}, \mathrm{EB}, \mathrm{ECM}$, and $\mathrm{BW}$ included the fixed (repeated) effect day relative to parturition (levels: d -25 to +42 ). The 2-way ANOVA model for analysis of metabolites and hormones contained the fixed effects body fluid (levels: plasma and cerebrospinal fluid), day relative to parturition (levels: -20 , $-10,+1,+10,+20$, and +40$)$, and their interaction. Post-hoc comparisons were performed using the TukeyKramer procedure for pairwise multiple comparisons. In addition, a model with the fixed effect body fluid (levels: plasma and cerebrospinal fluid), the covariate day relative to parturition (days: $-20,-10,+1,+10$, +20 , and +40$)$, and the interaction body fluid $\times$ day was used to estimate, test, and compare the intercepts and slopes of the trend lines for periparturient plasma and CSF variables to evaluate the parallel course of one variable in both body fluids. Resistin abundances were analyzed with a model comprising the fixed effect multimer (levels: tetramer, octamer, and hexamer), the covariate day relative to parturition, and the interac- tion multimer $x$ day. The intercepts and slopes of the trend lines for each multimer of resistin were estimated and tested. Effects and differences were considered significant if $P \leq 0.05$.

\section{RESULTS}

\section{Plasma and CSF Concentrations of Glucose, BHBA, Cholesterol, NEFA, Lactate, FFA, and VFA, and Osmolality}

The comparison between both body fluids revealed that osmolality (Figure 1) and all metabolite and hormone concentrations (Figures 1 to 3 ) mentioned in the following differed significantly between CSF and plasma. Plasma glucose and lactate continuously decreased after calving and remained lower in early lactation than in late pregnancy $(P<0.05$; Tukey test: -20 and -10 vs. 10, 20, and 40; Figure 1). In contrast, plasma concentrations of NEFA and BHBA continuously increased starting $10 \mathrm{~d}$ before calving until d 20 postpartum and then reached a plateau that was higher than that observed before parturition $(P<$ 0.05; Tukey test: -20 vs. $1,10,20$, and 40$)$. Percentages of free myristic acid (C14:0) and oleic acid (C18:1) in plasma significantly increased during the periparturient period, whereas percentages of palmitic acid (C16:0) and $\alpha$-linolenic acid (C18:3) significantly decreased $(P$ $<0.05$, ANOVA; Figure 1). Percentages of total SFA (Figure 1) decreased, whereas unsaturated FA percentages increased in plasma over the course of time $(P<$ 0.05, ANOVA).

Total VFA plasma concentrations, in particular acetic and propionic acid, significantly increased during the periparturient period, whereas n-butyric and n-valeric acid significantly decreased $(P<0.05$, ANOVA; Figure $1)$. The plasma cholesterol concentration decreased until calving and then increased thereafter to concentrations exceeding those measured before parturition $(P<0.05$; Tukey test: -20 and -10 vs. 1,20 , and 40$)$, whereas plasma osmolality tended to decrease $(P<0.1$, ANOVA) after calving.

Glucose and lactate concentrations in CSF decreased throughout the periparturient period $(P<0.05$, ANOVA), whereas CSF BHBA increased after calving ( $P$ $<0.05$, ANOVA). Cholesterol and NEFA concentrations and osmolality in CSF did not change during the periparturient period. In addition, courses of BHBA, cholesterol, NEFA, and lactate concentrations in both plasma and CSF did not run parallel to each other over time (Figure 1).

\section{Plasma and CSF Concentrations of AA and Urea}

Plasma concentrations of the free essential AA His significantly decreased throughout the periparturient 

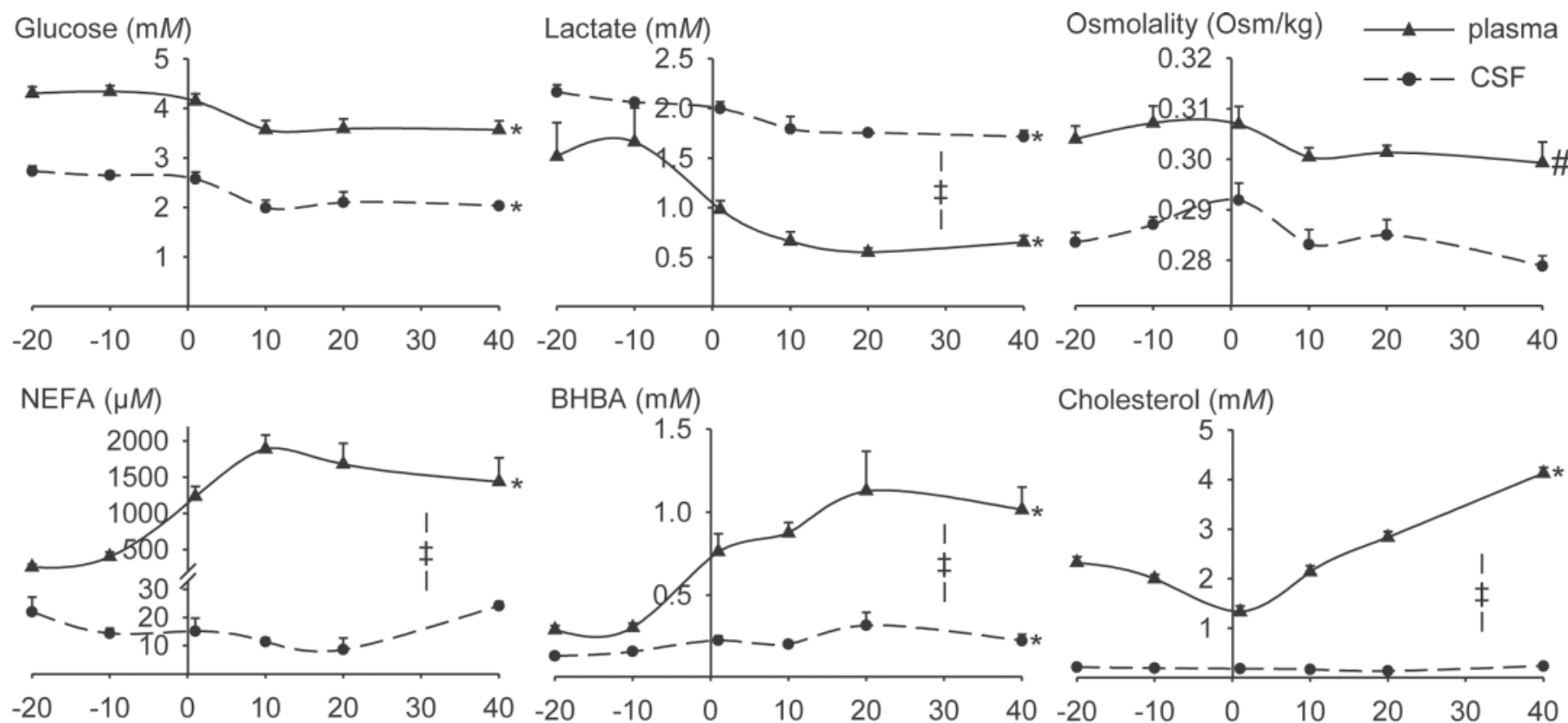

Cholesterol $(\mathrm{mM})$
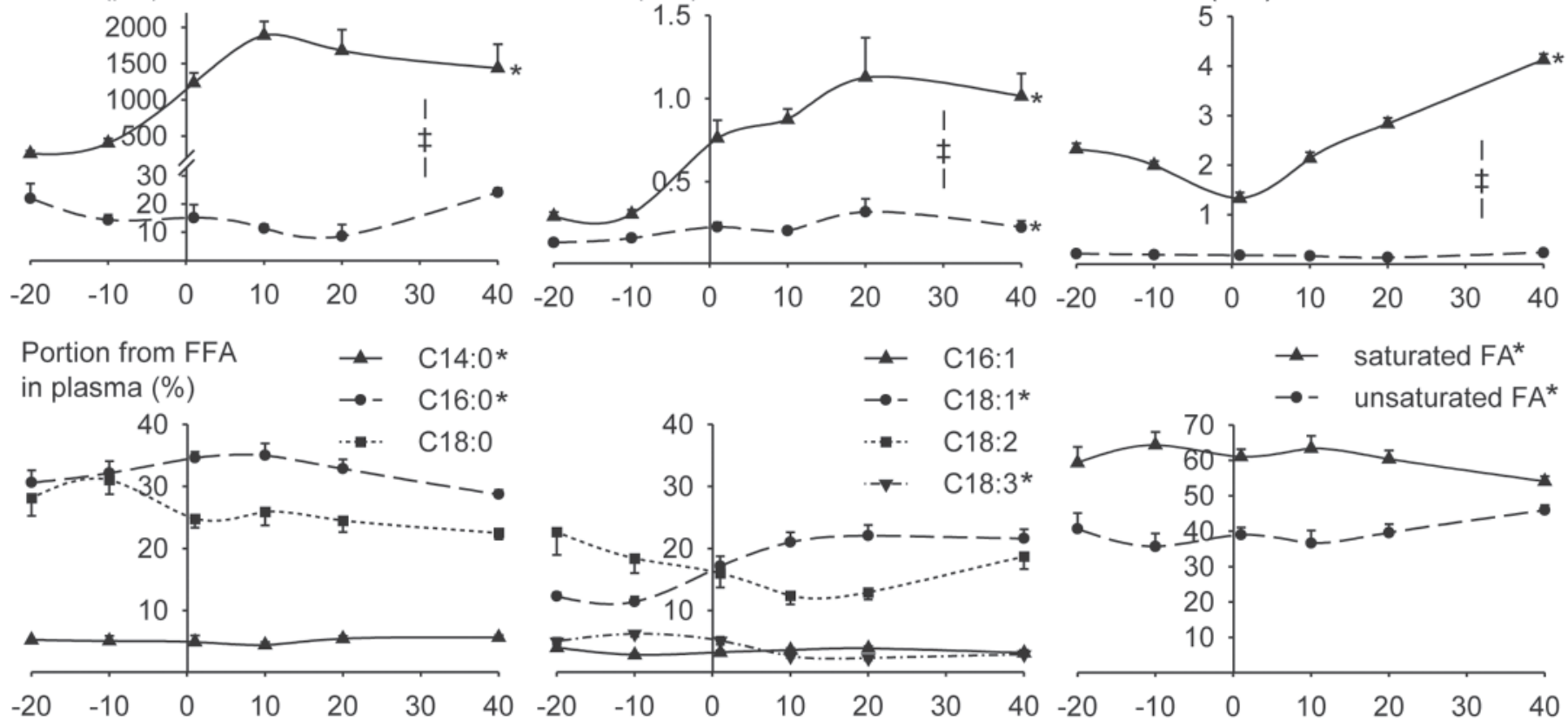

$\begin{aligned} \text { VFA in plasma }(\mu M) & \leftarrow \text { total* } \\ & \rightarrow-\text { Acetic acid }^{*}\end{aligned}$
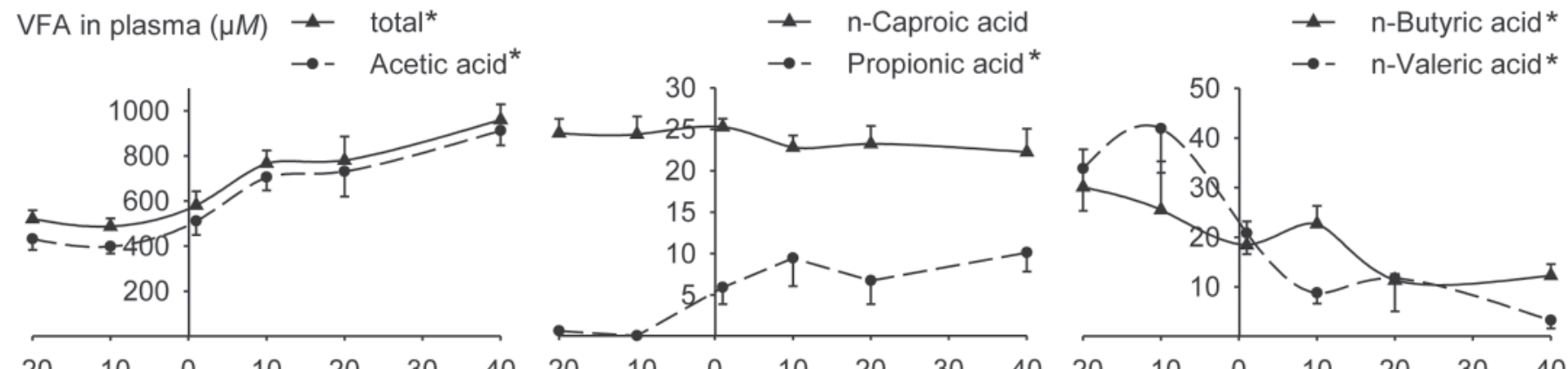

$\begin{array}{lllllll}-20 & -10 & 0 & 10 & 20 & 30 & 40\end{array}$

Days relative to parturition

Figure 1. Periparturient plasma and cerebrospinal fluid (CSF) concentrations of glucose, lactate, NEFA, BHBA, cholesterol, osmolality, and VFA (in plasma only) of dairy cows $(\mathrm{n}=10)$. Concentrations of saturated and unsaturated FFA in plasma are depicted as portion $(\%)$ from total FFA measured. Data are presented as the means \pm SE. $*$ indicates a significant slope $(P \leq 0.05)$ of the trend line, whereas \# indicates $0.05<P<0.1 ; \ddagger$ indicates significantly different slopes of plasma versus CSF trend lines.

period $(P<0.05$; Tukey test: -20 vs. 40 ; Figure $2 \mathrm{E})$, whereas Ile, Leu, and Val did not change significantly, but were lowest at the first day after calving $(P<0.05$; Tukey test: -10 vs. 1; Figure $2 \mathrm{~F}$ to $\mathrm{H}$ ). Furthermore, plasma concentration of the nonessential AA Gln was lower in early lactation than during late gestation $(P<$ 0.05; Tukey test: Gln -20 and -10 vs. 40; Figure $2 \mathrm{C}$ ). In contrast, plasma concentration of $\alpha$-aminobutyric acid ( $\mathbf{\alpha}$-ABA) increased starting $10 \mathrm{~d}$ before calving until d 40 postpartum $(P<0.05$; Tukey test: -10 vs. 
20 and 40; Figure 2A), whereas Gly concentration increased until d 20 postpartum $(P<0.05$; Tukey test: -20 and -10 vs. 10 and 20; Figure 2D).

In CSF, concentrations of $\alpha-\mathrm{ABA}$, Cit, Gly, and branched-chain AA (BCAA) increased during early lactation $(P<0.05$, ANOVA; Figure $2 \mathrm{~A}, \mathrm{~B}, \mathrm{D}$, and $\mathrm{J})$, the latter primarily due to the contribution of Ile and Val (Figure $2 \mathrm{~F}$ and $\mathrm{H})$, and less due to Leu $(P=$ 0.1, ANOVA; Figure 2G). The CSF essential AA His concentration tended to decrease throughout the periparturient period $(P<0.1$, ANOVA; Figure $2 \mathrm{E})$. The CSF Gln concentration tended to increase from day -20 prepartum to d 1 postpartum $(P<0.1$; Tukey test: -20 vs. 1 ; Figure $2 \mathrm{C})$ but decayed thereafter $(P<0.05$; Tukey test: 1 vs. 20 and 40). Interestingly, whereas in CSF total AA concentrations significantly decreased during early lactation $(P<0.05$, ANOVA; Figure 2I), total plasma AA concentration revealed a minimum only at the day after calving $(P<0.05$; Tukey-test: 1 vs. 10 and 20; Figure 2I). In contrast, plasma and CSF urea concentrations increased starting before calving until d 40 postpartum $(P<0.05$, ANOVA; Figure 2L). In summary, concentrations of His, $\alpha-\mathrm{ABA}$, Gly, and nonessential AA in both plasma and CSF did not run in parallel throughout the periparturient period.

\section{Plasma and CSF Concentrations of Ghrelin, Leptin, and Resistin}

In contrast to the time course of energy intake, plasma concentration of ghrelin did not change during the periparturient period in both CSF and plasma (ANOVA; Figure 3). On the other hand, CSF and plasma leptin concentrations decreased until calving and also remained lower in early lactation than before calving $(P<0.05$; Tukey test: plasma -20 and -10 vs. 1, 10, 20, and 40; Figure 3). Moreover, concentrations of leptin and ghrelin differed significantly in CSF compared with plasma, and the courses of leptin concentration in both plasma and CSF did not parallel each other throughout the periparturient period. In contrast to plasma, in CSF, only the resistin dimer was present, which did not change relative to calving. Total plasma resistin abundance continuously decreased throughout the period investigated $(P<0.05$, ANOVA; Figure 3$)$. However, neither the plasma resistin tetramer nor the octamer abundances were significantly altered.

\section{DISCUSSION}

\section{Glucose}

After restricted feeding of dairy cows, glucose tended to be reduced in CSF, whereas the blood plasma con- centration did not change (Laeger et al., 2012). In the present study, glucose concentrations decreased in both plasma and CSF after parturition, likely due to increased glucose utilization by the mammary gland. Thus, it seems that central glucose deficiency may elicit hunger, leading to the increase in FI that generally occurs during early lactation.

\section{$B H B A$}

Studies with goats revealed that the amount of intraperitoneally injected BHBA is related to hypophagia but this study could not clarify whether BHBA acts peripherally, centrally, or both to reduce FI (Rossi et al., 2000). The mechanism by which BHBA could trigger anorexic signaling in the brain may be divers. $\beta$-Hydroxybutyrate may enter the neuron and be oxidized, thereby generating ATP, which intracellularly triggers for anorexic signaling. In support of this mechanism, Kammula (1976) showed that BHBA is primarily oxidized by the sheep brain under hypoglycemic but less under normoglycemic conditions. On the other hand, Lindsay and Setchell (1976) reported that BHBA is only marginally metabolized by the sheep brain, excluding that BHBA would act as central metabolic signal confining FI. However, BHBA could affect intracellular signaling without entering the neuron by binding to the membrane $\mathrm{G}$ protein-coupled receptor 109A (GPR109A), which has been shown to be expressed in several portions of the cattle brain (Titgemeyer et al., 2011). No matter by which cellular mechanism BHBA acts to reduce FI (Rossi et al., 2000), from our results we conclude that increased CSF BHBA concentration could provide a signal for an insufficient increase in FI in early lactation.

\section{Cholesterol}

Plasma cholesterol concentrations increased after calving, presumably as the consequence of increased plasma high-density lipoproteins, rich in cholesterol (Bernabucci et al., 2004). The transport of cholesterol into the brain is impeded by its tight binding to plasma proteins and cholesterol, therefore, hardly crosses the brain capillary wall (Pardridge and Mietus, 1980). However, another study reported that cholesterol enters the brain, albeit slowly, suggesting that cholesterol may cross the BBB via the choroid plexus or other circumventricular organs in rodents (Serougne et al., 1976). Due to the unchanged periparturient CSF cholesterol concentration, it seems that cholesterol hardly enters the BBB in cows and, thus, cholesterol barely participates in FI control. 


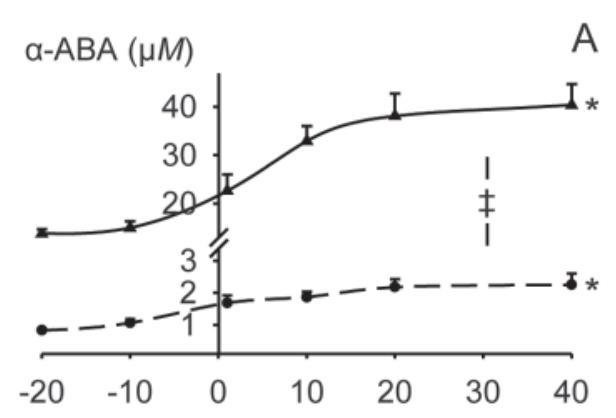

A $\operatorname{Cit}(\mu M)$

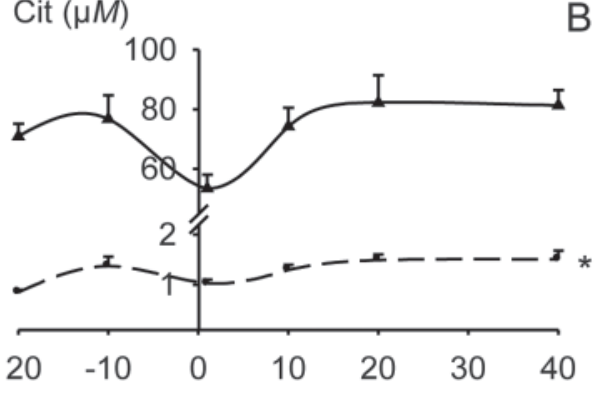

B $\ln (\mu M)$

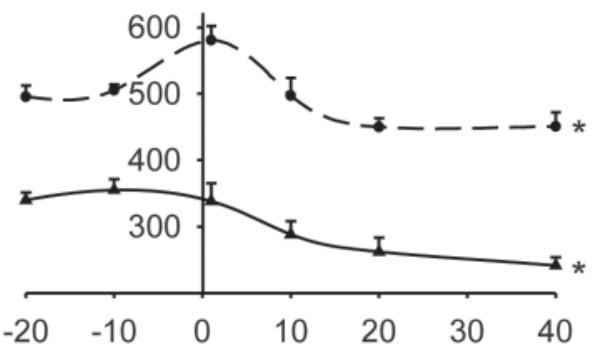

\section{Gly $(\mu M)$}

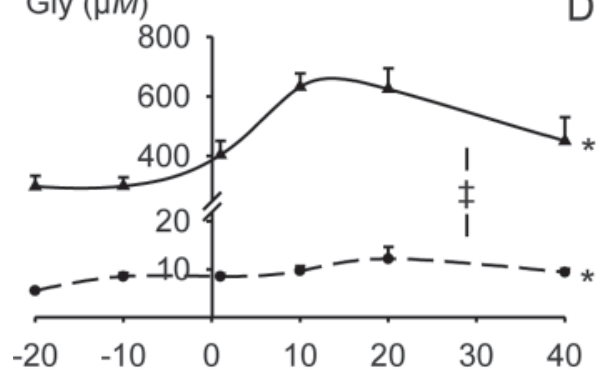

His $(\mu M)$

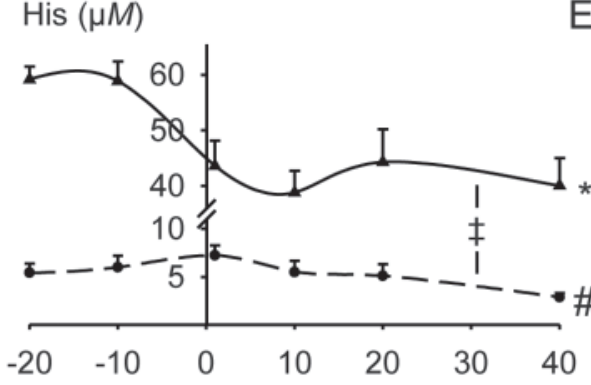

E lle $(\mu M)$
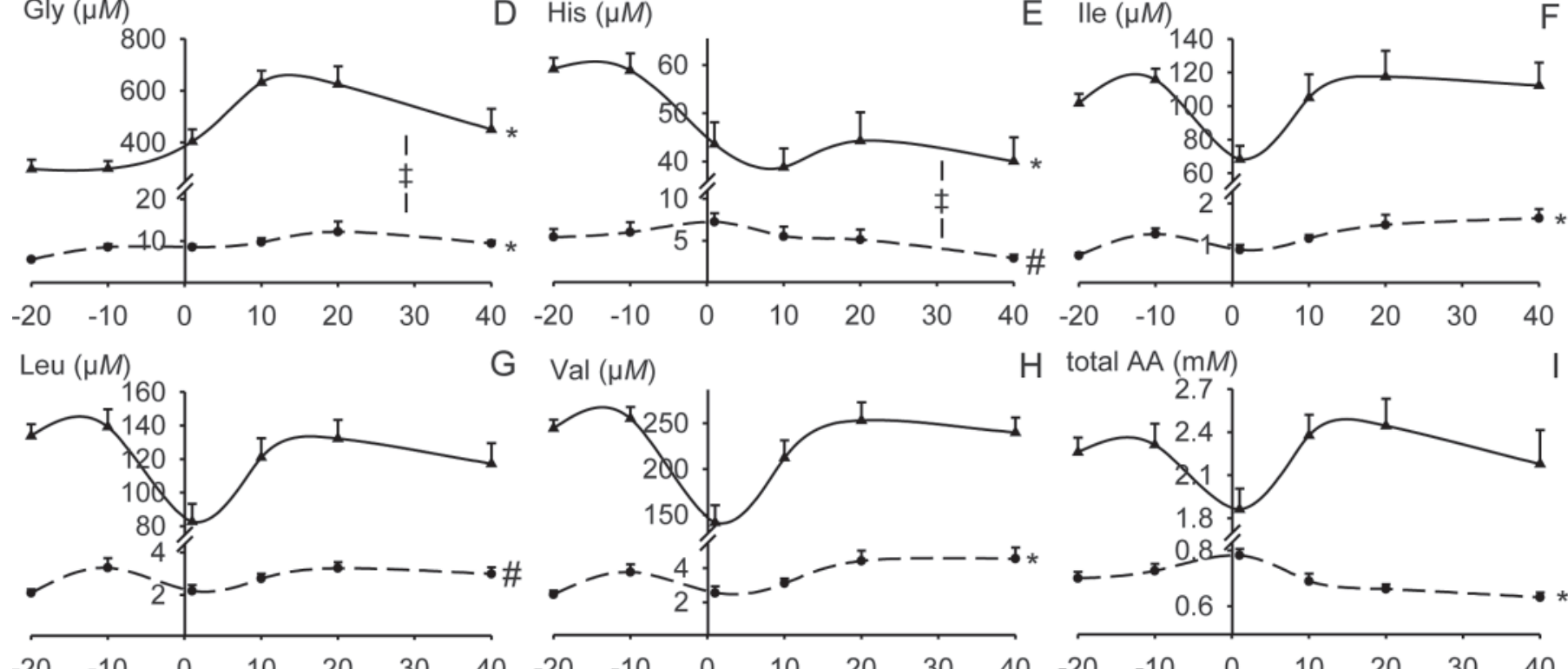

Val $(\mu M)$

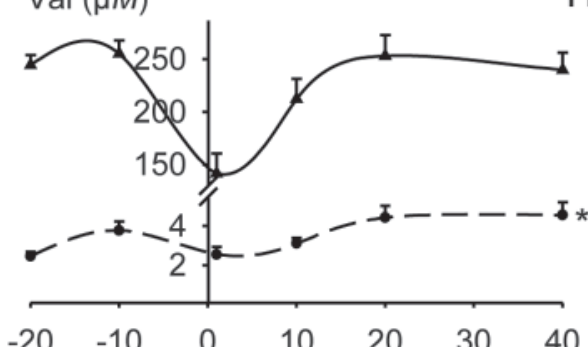

$\mathrm{H}$ total $\mathrm{AA}(\mathrm{mM})$
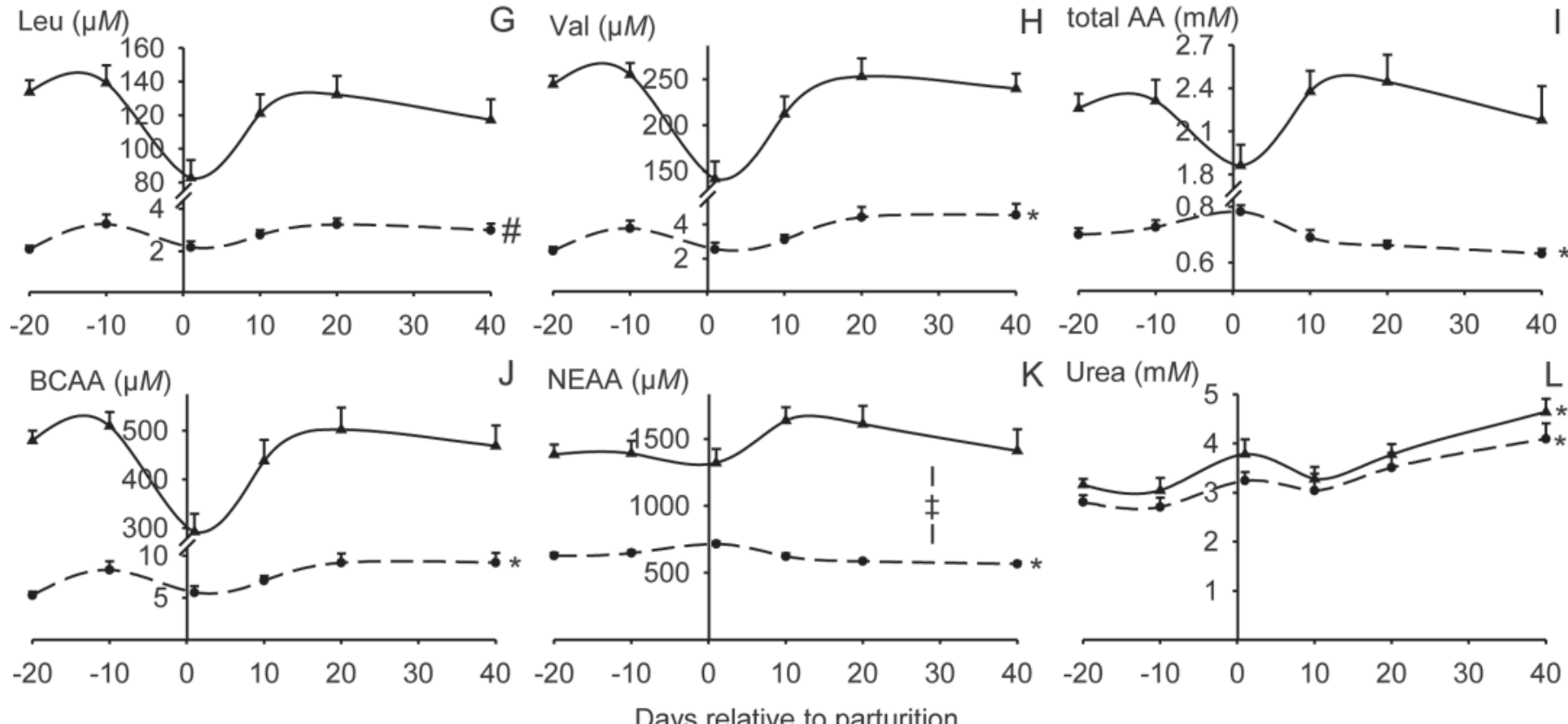

Days relative to parturition

Figure 2. Periparturient plasma and cerebrospinal fluid (CSF) AA and urea concentrations of dairy cows $(\mathrm{n}=9)$. Total AA concentration is calculated from the sum of 21 individual AA including Ala, $\alpha$-aminoadipic acid, $\alpha$-aminobutyric acid ( $\alpha$-ABA), anserine, Arg, Asn, Asp, $\beta$-Ala, carnosine, Cit, Cys, $\gamma$-aminobutyric acid, Gln, Glu, Gly, His, hydroxyproline, Ile, Leu, Lys, Met, Orn, Phe, Pro, Ser, Thr, Trp, Tyr, Val, and 1- and 3-methylhistidine (for further details see Supplementary Figures S1 and S2, available online at http://www.journalofdairyscience.org/). Data are presented as the means $\pm \mathrm{SE}, *$ indicates a significant slope $(P \leq 0.05)$ of the trend line, whereas $\#$ indicates $0.05<P<0.1 ; \ddagger$ indicates significantly different slopes of plasma versus CSF trend lines. BCAA = branched-chain AA; NEAA = nonessential AA.

\section{NEFA}

Infusion (intravenous) of palmitic (C16:0) and oleic acid (C18:1) resulted in a significant decrease in FI in sheep (Vandermeerschen-Doizé and Paquay, 1984).
Percentages of C16:0 decreased during the periparturient period, indicating that peripheral C16:0 does not negatively influence FI during early lactation. We found elevated plasma C18:1 concentrations around and after parturition which likely act as a peripheral signal, pre- 

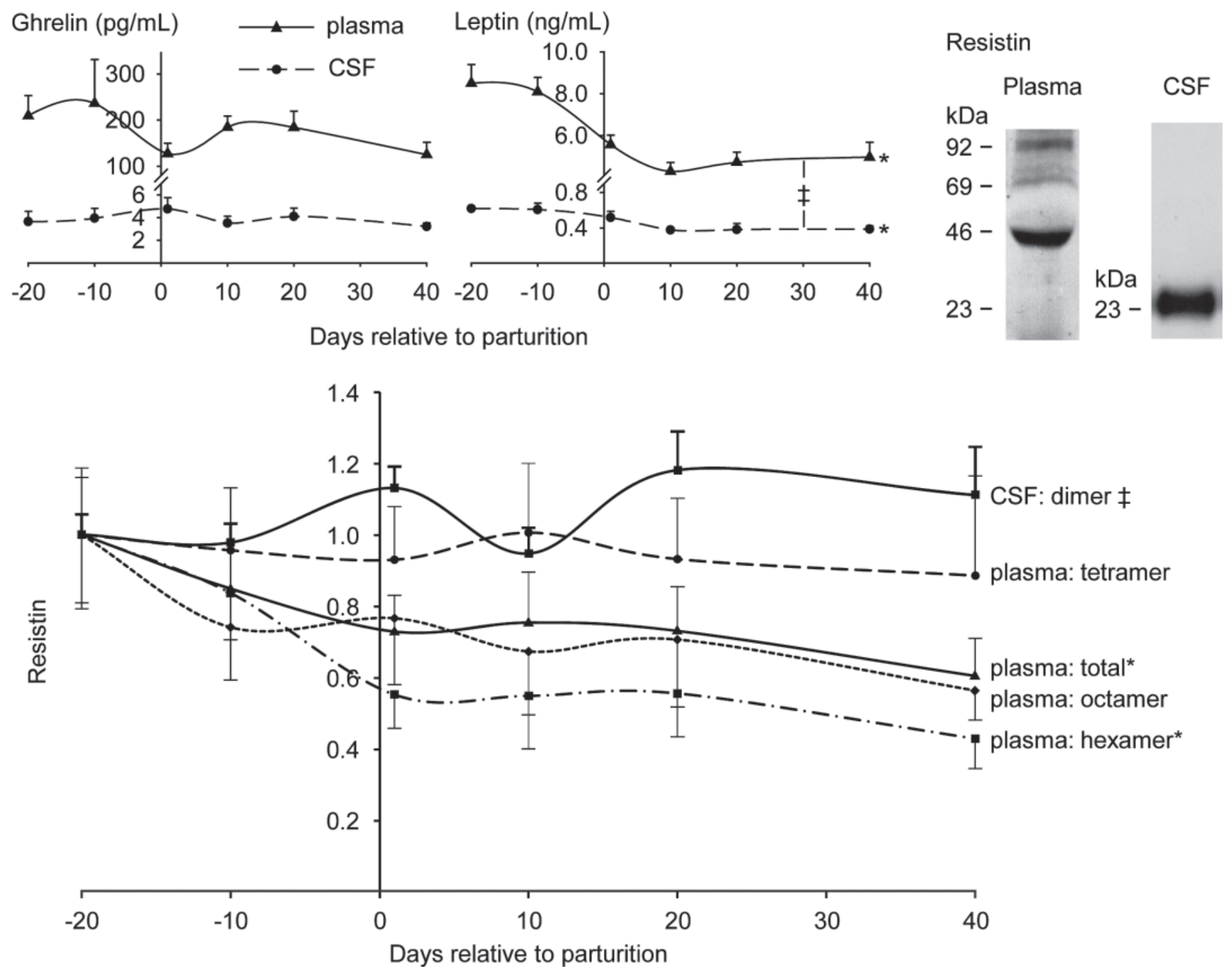

Figure 3. Periparturient plasma and cerebrospinal fluid (CSF) ghrelin and leptin concentrations measured by RIA and ELISA, respectively $(\mathrm{n}=6-7)$, and resistin levels of dairy cows determined by Western immunoblot analysis $(\mathrm{n}=10)$. Resistin data are normalized to the abundances of d 20 antepartum and all data are presented as the means \pm SE. * indicates a significant slope $(P \leq 0.05)$ of the trend line; $\ddagger$ indicates significantly different slopes of plasma versus CSF trend lines.

venting sufficient FI in early lactation. Whether FA may also act directly at the brain as recently proposed (Lam et al., 2005) remains speculative. Our present finding shows that despite elevated plasma NEFA concentrations after calving, CSF NEFA concentrations did not change during the periparturient period. Therefore, it seems unlikely that NEFA cross the BBB and act directly at feed intake-regulatory centers in the brain to elicit anorexic responses.

\section{Lactate}

From an earlier study we have concluded that circulating lactate does not play a major role in the FI regulatory circuits of cows because, in both CSF and plasma, the concentrations did not change after feed restriction (Laeger et al., 2012). Also intravenous injections of lactate did not change FI in dairy cattle significantly (Dowden and Jacobson, 1960). In the brain, lactate is produced by astrocytes to serve as a fuel for neurons. This might explain the higher lactate concentration in CSF compared with plasma. The decrease in CSF lactate concentration observed in early lactation could, thus, be a result of either increased neuronal lactate consumption, decreased astrocyte lactate production, or due to an enforced lactate flow from the brain to peripheral organs during times of enhanced glucose needs. 


\section{$A A$}

Feed-restricted dairy cows entering a negative EB had a lower total CSF AA concentration (Laeger et al., 2012), which is in accordance with the present finding in which we report a decrease in total AA concentration in CSF during early lactation. This is primarily the result of decreasing CSF Gln concentrations (the major AA in CSF), presumably because Gln serves also as the major AA for milk production. However, besides glucose, lactate, and BHBA, Gln may also serve as energy substrate for the brain so that the slight Gln peak in CSF around parturition could either be the result of increased CSF Gln uptake or increased expression of glutamine synthetase, such as described for the late pregnancy of rats (Salmaso et al., 2011). Accumulating Gln concentrations may increasingly be utilized for ATP production, the latter leading to satiety (Kola, 2008). Thus, CSF Gln, which, in contrast to other AA, increased until d 1 postpartum, may act as a central anorexigenic signal shortly before parturition. However, the effect of central administration of Gln on FI has not been investigated yet. The conversion of His to neuronal histamine suppresses FI (Yoshimatsu et al., 2002). Because CSF His concentrations tended to decrease throughout the periparturient period, it seems unlikely that central His plays a major role in preventing sufficient increase in FI in early lactation. Abomasal infusion of BCAA did not affect FI of lactating cows fed ad libitum (Korhonen et al., 2002), suggesting that dietary BCAA are not important controllers for FI of cows. However, Leu suppresses FI when administered directly into the brain of rodents (Morrison et al., 2007). When compared with the antepartum period, Leu tended to increase in CSF after calving, whereas plasma Leu concentration was unchanged. Hence, central but not peripheral Leu may contribute to the inadequate FI in early lactation. Due to the increased CSF concentrations of Ile and Val after parturition, it cannot be excluded that these BCAA also possess central anorexigenic characteristics in cows, although in rodents, central infusion of Val did not affect FI (Cota et al., 2006). Similar to BCAA, CSF Gly, Cit, and $\alpha$-ABA concentrations were higher during early lactation compared with the antepartum period but whether these AA may influence FI by exerting central anorexic signaling is not known.

\section{VFA}

Infusions of acetate into the jugular or mesenteric vein had no effect on FI (Allen, 2000), whereas infusion of propionate into the jugular vein of ruminants reduced FI (Dowden and Jacobson, 1960). In the present study, we observed increased propionic acid plasma concentrations during early lactation, suggesting a role for propionate in preventing sufficient increase in FI. However, we were not able to determine propionate concentration in CSF and, thus, cannot conclude if propionate has a central effect on satiety.

\section{Osmolality}

Central (i.c.v.) infusion of hypertonic $\mathrm{NaCl}$ solution decreased FI in cattle (McKinley et al., 1987). Our findings of an unchanged CSF osmolality throughout the periparturient period eliminate the possibility that altered salt concentrations are involved in insufficient FI in early lactation.

\section{Ghrelin}

Plasma ghrelin concentrations increased in response to feed deprivation and decreased after feeding in cows (Hayashida et al., 2001). Furthermore, basal plasma ghrelin concentrations decreased from early to late lactation (Itoh et al., 2005), whereas negative EB has been suggested to increase ghrelin concentrations (Itoh et al., 2005; Bradford and Allen, 2008). However, this increase was only seen upon feed deprivation in early lactation (Bradford and Allen, 2008). In this regard, our results are in accordance with these earlier studies showing that basal plasma ghrelin concentrations in early lactation are not significantly elevated. In addition, reports about the central effect of ghrelin on FI in ruminants are inconsistent: either ghrelin had no effect (Iqbal et al., 2006) or it slightly increased (Harrison et al., 2008) FI. Our finding of unaltered CSF ghrelin concentrations around parturition indicates that central ghrelin does not support the increase in FI observed after parturition.

\section{Leptin}

Leptin is released from adipose tissue and binds at its receptor located in the hypothalamus to reduce FI in ruminants (Morrison et al., 2001). Considering decreasing leptin CSF concentration from pregnancy to parturition, it can be assumed that central leptin signals to promote hyperphagia during early lactation, which is in line with earlier reports for the lactating sheep (Sorensen et al., 2002).

\section{Resistin}

Resistin is mainly secreted by adipocytes but also by the hypothalamus and the pituitary (Adeghate, 2004). It was hypothesized that resistin may play a role in the control of FI in dairy cows because of decreased 
CSF resistin dimer concentrations upon feed restriction (Laeger and Kuhla, 2011). Our present finding of unchanged CSF resistin dimer concentrations indicates that resistin has no major role in the central control of FI around parturition.

\section{CONCLUSIONS}

To summarize, we investigated a range of hormones and metabolites in CSF and plasma of cows during the periparturient period. Earlier studies deduced the orexigenic and anorexigenic effects of hormones and metabolites primarily from plasma data. Here, we demonstrated that some hormones (resistin and leptin) and metabolites (BHBA, cholesterol, NEFA, lactate, $\mathrm{\alpha}$-ABA, Cit, Gly, His, Ile, and Val) showed different responses during the periparturient period, either in plasma or CSF. This is presumably due to a different permeability of the BBB bordering the periphery from brain and due to an altered energy metabolism of the brain. Because of the known anorexic effects and increased CSF concentration of BHBA and Leu during early lactation, we propose that this adaptational response may contribute to the insufficient FI during early lactation by diminishing hunger or increasing satiety. Because CSF Gln concentrations tended to increase until calving, it seems that CSF Gln may act as a central anorexigenic signal shortly before parturition.

\section{ACKNOWLEDGMENTS}

We thank M. Althaus, C. Arlt, K. Karpati, A.-K. Möller, C. Plinski, C. Reiko, B. Sobczak, and the staff of the Tiertechnikum [all of the Leibniz Institute for Farm Animal Biology (FBN), Dummerstorf, Germany] for their skillful assistance and excellent technical support. B. Mielenz (Bonn University, Bonn, Germany) and S. Bühler (University of Rostock, Rostock, Germany) are acknowledged for support in leptin and osmolality measurements, respectively. Linguistic refinements of the text by A. Myers are gratefully acknowledged. This research did not receive any specific grant from any funding agency in the public, commercial or not-forprofit sector. This work was supported by the Leibniz Institute for Farm Animal Biology.

\section{REFERENCES}

Adeghate, E. 2004. An update on the biology and physiology of resistin. Cell. Mol. Life Sci. 61:2485-2496.

Allen, M. S. 2000. Effects of diet on short-term regulation of feed intake by lactating dairy cattle. J. Dairy Sci. 83:1598-1624.

Baile, C. A., and J. M. Forbes. 1974. Control of feed intake and regulation of energy balance in ruminants. Physiol. Rev. 54:160-214.

Banks, W. A., M. Tschöp, S. M. Robinson, and M. L. Heiman. 2002. Extent and direction of ghrelin transport across the blood-brain barrier is determined by its unique primary structure. J. Pharmacol. Exp. Ther. 302:822-827.

Bernabucci, U., B. Ronchi, L. Basiricò, D. Pirazzi, F. Rueca, N. Lacetera, and A. Nardone. 2004. Abundance of mRNA of apolipoprotein $\mathrm{B}_{100}$, apolipoprotein $\mathrm{E}$, and microsomal triglyceride transfer protein in liver from periparturient dairy cows. J. Dairy Sci. $87: 2881-2888$

Bradford, B. J., and M. S. Allen. 2008. Negative energy balance increases periprandial ghrelin and growth hormone concentrations in lactating dairy cows. Domest. Anim. Endocrinol. 34:196-203.

Cifani, C., Y. Durocher, A. Pathak, L. Penicaud, F. Smih, M. Massi, P. Rouet, and C. Polidori. 2009. Possible common central pathway for resistin and insulin in regulating food intake. Acta Physiol. (Oxf.) 196:395-400.

Costa, C. G., L. Dorland, U. Holwerda, I. T. de Almeida, B.-T. PollThe, C. Jakobs, and M. Duran. 1998. Simultaneous analysis of plasma free fatty acids and their 3-hydroxy analogs in fatty acid beta-oxidation disorders. Clin. Chem. 44:463-471.

Cota, D., K. Proulx, K. A. Blake Smith, S. C. Kozma, G. Thomas, S. C. Woods, and R. J. Seeley. 2006. Hypothalamic mTOR signaling regulates food intake. Science 312:927-930.

Dowden, D. R., and D. R. Jacobson. 1960. Inhibition of appetite in dairy cattle by certain intermediate metabolities. Nature 188:148-149.

Fry, M., and A. V. Ferguson. 2010. Ghrelin: Central nervous system sites of action in regulation of energy balance. Int. J. Pept. 2010:616757.

German Society of Nutrition Physiology. 2001. Ausschuss für Bedarfsnormen der Gesellschaft für Ernährungsphysiologie, No. 8. Empfehlungen zur Energie- und Nährstoffversorgung der Milchkühe und Aufzuchtrinder (Recommended Energy and Nutrient Supply for Dairy Cows and Growing Cattle). DLG-Verlag, Frankfurt am Main, Germany.

Harper, A. E., and J. C. Peters. 1989. Protein intake, brain amino acid and serotonin concentrations and protein self-selection. J. Nutr. 119:677-689.

Harrison, J. L., D. W. Miller, P. A. Findlay, and C. L. Adam. 2008 Photoperiod influences the central effects of ghrelin on food intake, GH and LH secretion in sheep. Neuroendocrinology 87:182-192.

Hayashida, T., K. Murakami, K. Mogi, M. Nishihara, M. Nakazato, M. S. Mondal, Y. Horii, M. Kojima, K. Kangawa, and N. Murakami. 2001. Ghrelin in domestic animals: Distribution in stomach and its possible role. Domest. Anim. Endocrinol. 21:17-24.

Ingvartsen, K. L. 2006. Feeding- and management-related diseases in the transition cow: Physiological adaptations around calving and strategies to reduce feeding-related diseases. Anim. Feed Sci. Technol. 126:175-213.

Iqbal, J., Y. Kurose, B. Canny, and I. J. Clarke. 2006. Effects of central infusion of ghrelin on food intake and plasma levels of growth hormone, luteinizing hormone, prolactin, and cortisol secretion in sheep. Endocrinology 147:510-519.

Itoh, F., T. Komatsu, M. Yonai, T. Sugino, M. Kojima, K. Kangawa, Y. Hasegawa, Y. Terashima, and K. Hodate. 2005. GH secretory responses to ghrelin and GHRH in growing and lactating dairy cattle. Domest. Anim. Endocrinol. 28:34-45.

Kammula, R. G. 1976. Metabolism of ketone bodies by ovine brain in vivo. Am. J. Physiol. 231:1490-1494.

Kola, B. 2008. Role of AMP-activated protein kinase in the control of appetite. J. Neuroendocrinol. 20:942-951.

Korhonen, M., A. Vanhatalo, and P. Huhtanen. 2002. Evaluation of isoleucine, leucine, and valine as a second-limiting amino acid for milk production in dairy cows fed grass silage diet. J. Dairy Sci. 85:1533-1545.

Kos, K., A. L. Harte, N. F. da Silva, A. Tonchev, G. Chaldakov, S. James, D. R. Snead, B. Hoggart, J. P. O'Hare, P. G. McTernan, and S. Kumar. 2007. Adiponectin and resistin in human cerebrospinal fluid and expression of adiponectin receptors in the human hypothalamus. J. Clin. Endocrinol. Metab. 92:1129-1136.

Kristensen, N. B., S. G. Pierzynowski, and A. Danfær. 2000. Net portal appearance of volatile fatty acids in sheep intraruminally in- 
fused with mixtures of acetate, propionate, isobutyrate, butyrate, and valerate. J. Anim. Sci. 78:1372-1379.

Kuhla, B., M. Kucia, S. Görs, D. Albrecht, M. Langhammer, S. Kuhla, and C. C. Metges. 2010. Effect of a high-protein diet on food intake and liver metabolism during pregnancy, lactation and after weaning in mice. Proteomics 10:2573-2588.

Laeger, T., S. Görs, C. C. Metges, and B. Kuhla. 2012. Effect of feed restriction on metabolites in cerebrospinal fluid and plasma of dairy cows. J. Dairy Sci. 95:1198-1208.

Laeger, T., and B. Kuhla. 2011. Feed restriction in dairy cows affects resistin levels in plasma and cerebrospinal fluid. Proc. Soc. Nutr. Physiol. 20:141.

Lam, T. K., G. J. Schwartz, and L. Rossetti. 2005. Hypothalamic sensing of fatty acids. Nat. Neurosci. 8:579-584.

Lindsay, D. B., and B. P. Setchell. 1976. The oxidation of glucose, ketone bodies and acetate by the brain of normal and ketonaemic sheep. J. Physiol. 259:801-823.

McKinley, M. J., D. A. Denton, D. Gellatly, R. R. Miselis, J. B. Simpson, and R. S. Weisinger. 1987. Water drinking caused by intracerebroventricular infusions of hypertonic solutions in cattle. Physiol. Behav. 39:459-464.

Morrison, C. D., J. A. Daniel, B. J. Holmberg, J. Djiane, N. Raver, A. Gertler, and D. H. Keisler. 2001. Central infusion of leptin into well-fed and undernourished ewe lambs: Effects on feed intake and serum concentrations of growth hormone and luteinizing hormone. J. Endocrinol. 168:317-324.

Morrison, C. D., R. Wood, E. L. McFadin, N. C. Whitley, and D. H. Keisler. 2002. Effect of intravenous infusion of recombinant ovine leptin on feed intake and serum concentrations of GH, LH, insulin, IGF-1, cortisol, and thyroxine in growing prepubertal ewe lambs. Domest. Anim. Endocrinol. 22:103-112.

Morrison, C. D., X. Xi, C. L. White, J. Ye, and R. J. Martin. 2007. Amino acids inhibit Agrp gene expression via an mTOR-dependent mechanism. Am. J. Physiol. Endocrinol. Metab. 293:E165-E171.

Pardridge, W. M., and L. J. Mietus. 1980. Palmitate and cholesterol transport through the blood-brain barrier. J. Neurochem. 34:463466 .
Reist, M., D. Erdin, D. von Euw, K. Tschuemperlin, H. Leuenberger, Y. Chilliard, H. M. Hammon, C. Morel, C. Philipona, Y. Zbinden, N. Kuenzi, and J. W. Blum. 2002. Estimation of energy balance at the individual and herd level using blood and milk traits in highyielding dairy cows. J. Dairy Sci. 85:3314-3327.

Rossi, R., S. D. Örig, E. Del Prete, and E. Scharrer. 2000. Suppression of feed intake after parenteral administration of D- $\beta$ hydroxybutyrate in pygmy goats. J. Vet. Med. A Physiol. Pathol. Clin. Med. 47:9-16.

Salmaso, N., M. P. Cossette, and B. Woodside. 2011. Pregnancy and maternal behavior induce changes in glia, glutamate and its metabolism within the cingulate cortex. PLoS ONE 6:e23529.

Sauerwein, H., U. Heintges, A. Hennies, T. Selhorst, and A. Daxenberger. 2004. Growth hormone induced alterations of leptin serum concentrations in dairy cows as measured by a novel enzyme immunoassay. Livest. Prod. Sci. 87:189-195.

Seoane, J. R., and C. A. Baile. 1972. Effects of intraventricular (3 ventricle) injections of 2-deoxy-D-glucose, glucose and xylose on feeding behavior of sheep. Physiol. Behav. 9:423-428.

Serougne, C. C. Lefevre, and F. Chevallier. 1976. Cholesterol transfer between brain and plasma in the rat: A model for the turnover of cerebral cholesterol. Exp. Neurol. 51:229-240.

Sorensen, A., C. L. Adam, P. A. Findlay, M. Marie, L. Thomas, M. T. Travers, and R. G. Vernon. 2002. Leptin secretion and hypothalamic neuropeptide and receptor gene expression in sheep. Am. J. Physiol. Regul. Integr. Comp. Physiol. 282:R1227-R1235.

Titgemeyer, E. C., L. K. Mamedova, K. S. Spivey, J. K. Farney, and B. J. Bradford. 2011. An unusual distribution of the niacin receptor in cattle. J. Dairy Sci. 94:4962-4967.

Vandermeerschen-Doizé, F., and R. Paquay. 1984. Effects of continuous long-term intravenous infusion of long-chain fatty acids on feeding behaviour and blood components of adult sheep. Appetite 5:137-146.

Yoshimatsu, H., S. Chiba, D. Tajima, Y. Akehi, and T. Sakata. 2002. Histidine suppresses food intake through its conversion into neuronal histamine. Exp. Biol. Med. (Maywood) 227:63-68. 